\title{
Qualitative and Quantitative Control of Honeys Using NMR Spectroscopy and Chemometrics
}

\author{
Marc Ohmenhaeuser, ${ }^{1}$ Yulia B. Monakhova, ${ }^{2,3,4}$ \\ Thomas Kuballa, ${ }^{2}$ and Dirk W. Lachenmeier ${ }^{2,5}$ \\ ${ }^{1}$ Chemisches und Veterinäruntersuchungsamt (CVUA) Freiburg, Bissierstraße 5, 79114 Freiburg, Germany \\ ${ }^{2}$ Chemisches und Veterinäruntersuchungsamt (CVUA) Karlsruhe, Weissenburger Straße 3, 76187 Karlsruhe, Germany \\ ${ }^{3}$ Bruker BioSpin GmbH, Silberstreifen, 76287 Rheinstetten, Germany \\ ${ }^{4}$ Department of Chemistry, Saratov State University, Astrakhanskaya Street 83, Saratov 410012, Russia \\ ${ }^{5}$ Ministry of Rural Affairs and Consumer Protection, Kernerplatz 10, 70182 Stuttgart, Germany
}

Correspondence should be addressed to Dirk W. Lachenmeier; lachenmeier@web.de

Received 21 March 2013; Accepted 16 April 2013

Academic Editors: A. Bouklouze, S. E. Jorge-Villar, W. X. Misiuk, A. Orte, Y. van der Burgt, and W. M. Winnik

Copyright (C) 2013 Marc Ohmenhaeuser et al. This is an open access article distributed under the Creative Commons Attribution License, which permits unrestricted use, distribution, and reproduction in any medium, provided the original work is properly cited.

$400 \mathrm{MHz}$ nuclear magnetic resonance (NMR) spectroscopy and multivariate data analysis techniques were used in the context of food surveillance to measure 328 honey samples with ${ }^{1} \mathrm{H}$ and ${ }^{13} \mathrm{C}$ NMR. Using principal component analysis (PCA), clusters of honeys from the same botanical origin were observed. The chemical shifts of the principal monosaccharides (glucose and fructose) were found to be mostly responsible for this differentiation. Furthermore, soft independent modeling of class analogy (SIMCA) and partial least squares discriminant analysis (PLS-DA) could be used to automatically classify spectra according to their botanical origin with 95-100\% accuracy. Direct quantification of 13 compounds (carbohydrates, aldehydes, aliphatic and aromatic acids) was additionally possible using external calibration curves and applying TSP as internal standard. Hence, NMR spectroscopy combined with chemometrics is an efficient tool for simultaneous identification of botanical origin and quantification of selected constituents of honeys.

\section{Introduction}

Honey is a natural, sweet, and syrupy fluid collected by bees from nectar of flowers [1]. The taste and aroma of this liquid vary according to its floral origin, geographical and seasonal conditions [1]. The large number of melliferous sources gives therefore the opportunity to produce many characteristical unifloral and a high number of polyfloral nectar honeys.

Each honey is unique on the basis of chemistry, amount, and combination of the various components that give each honey a unique and individual organoleptic character. The control and characterization of quality and botanical origin of unifloral honeys are of great importance and interest in apiculture. Today the most important techniques to determine or certify the unifloral origin of honeys are the melissopalynological analysis and the evaluation of organoleptic characteristics [2]. Current quality assessment of honey by these methods are time-consuming and often operator dependent. Moreover, some types of adulterations (e.g., the addition of sugar concentrate to honey) can hardly be detected with such methods [3].

Various novel, fast, and accurate chromatographic methods such as high-performance liquid chromatography (HPLC) [4-7], gas chromatography (GC) [8-10], liquid chromatography with electrochemical detector [11], and matrixassisted-laser-desorption/ionization-time-of-flight-mass-spectrometry (MALDI TOF MS) [12,13] have been used to obtain the chemical composition and detect possible adulteration of honey. Vibration spectroscopic methods such as FT-Raman $[14,15]$, NIR [16-18], and FT-IR [19-21] could be additionally used as a screening technique for checking the honey authenticity and for quantifying its major compounds.

Apart from these analytical methods, the application of multivariate data analysis and, in particular, principal 


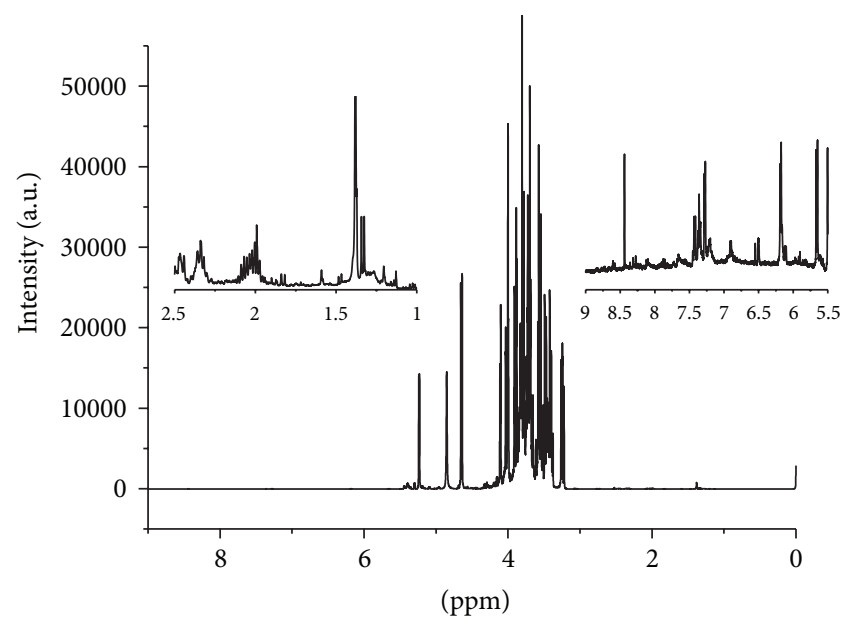

(a)

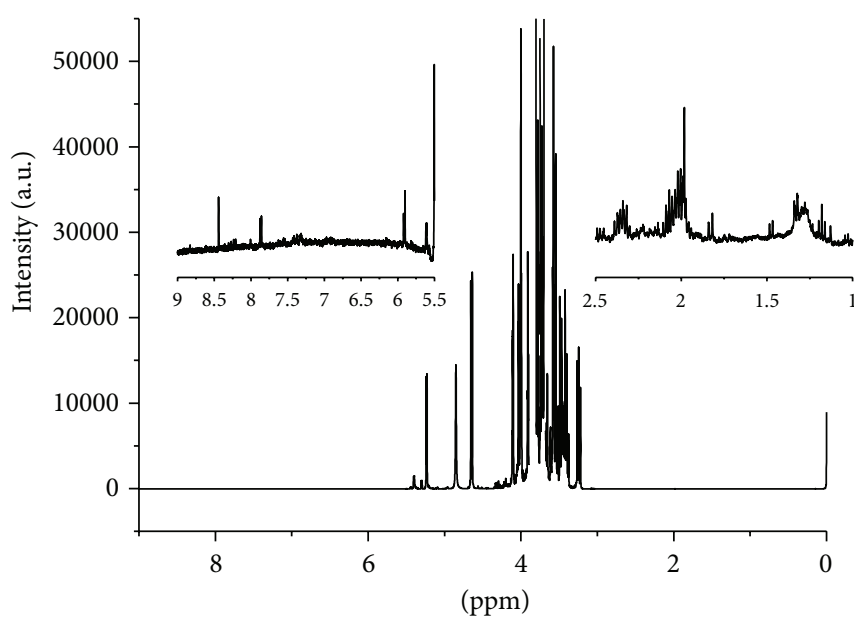

(b)

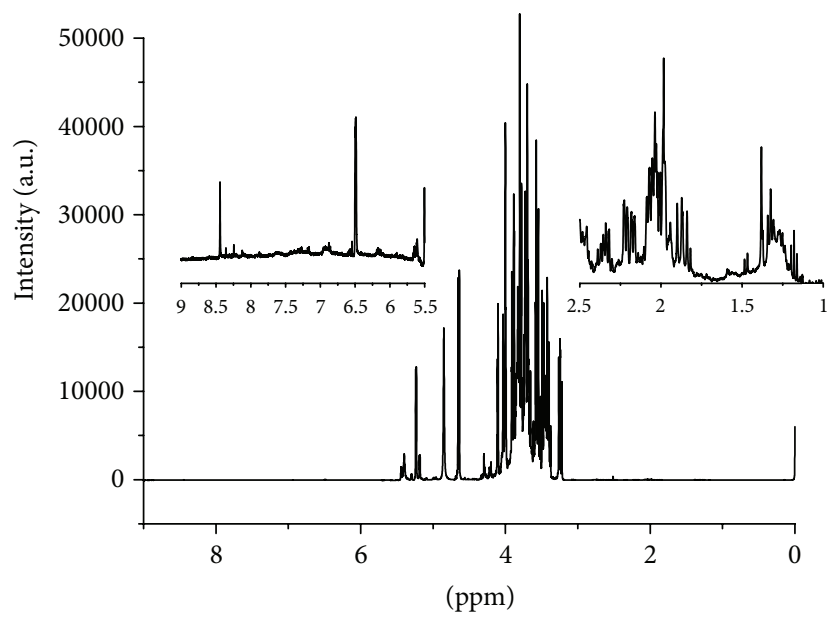

(c)

Figure 1: ${ }^{1} \mathrm{H}$ NMR spectra of Tilia (a), Robinia pseudoacacia (b), and fir (c) honeys. The inserts show expansions of the spectral regions $\delta$ 2.5-1.0 ppm and $\delta 9.0-5.5 \mathrm{ppm}$.

component analysis (PCA) [9, 22], canonical variate analysis (CLA) [8, 23], partial least squares (PLS) regression [17, 24, 25], principal component regression (PCR) [17], linear discriminant analysis (LDA) [22], and soft independent modeling class analogy (SIMCA) [25] proved to be extremely useful for grouping and detecting honey from different origins. Besides these multivariate methods, modern sensor techniques such as electronic nose (e-nose) and electronic tongue (e-tongue) were successfully applied to classify honey samples according to their floral origin [3].

Nuclear magnetic resonance (NMR) spectroscopy has been also used to assess the botanical origin of honey and quantify some major compounds in it [26-30]. It was shown that NMR has a good potential to become a useful quality control tool in the analysis of honey samples. However, the number of floral honey types and the total number of investigated samples have been insufficient to construct a good discrimination model for routine analysis. Targeted quantitative NMR analysis was limited to major carbohydrates and amino acids [27, 31]. Therefore, this paper further advances the investigation of a combined NMR spectroscopy $\left({ }^{1} \mathrm{H}\right.$ and ${ }^{13} \mathrm{C}$ NMR) and chemometric data analysis approach to distinguish the botanical origin of honey. We also explored the potential of high-resolution ${ }^{1} \mathrm{H}$ NMR to allow the identification and the quantification of 13 selected components in honeys.

\section{Experimental}

2.1. Samples and Chemicals. A total of 328 samples from different botanical origins were analyzed using NMR. The samples were randomly selected by governmental food inspectors from Baden-Württemberg, Germany, from honey bottling plants, supermarkets and directly by bee keepers. The following reference standards were used in proanalysis quality: hydroxymethylfurfural (HMF), fumaric acid, citric acid, malic acid, erlose, melibiose, xylitol, oxalic acid (anhydrous), D-glucuronic acid, DL-lactic acid (Sigma Aldrich, Steinheim, Germany); formic acid, phthalic acid, and glucose, $\mathrm{L}(+)$-tartaric acid, fructose, $\mathrm{D}(+)$-galactose, maltose, and 


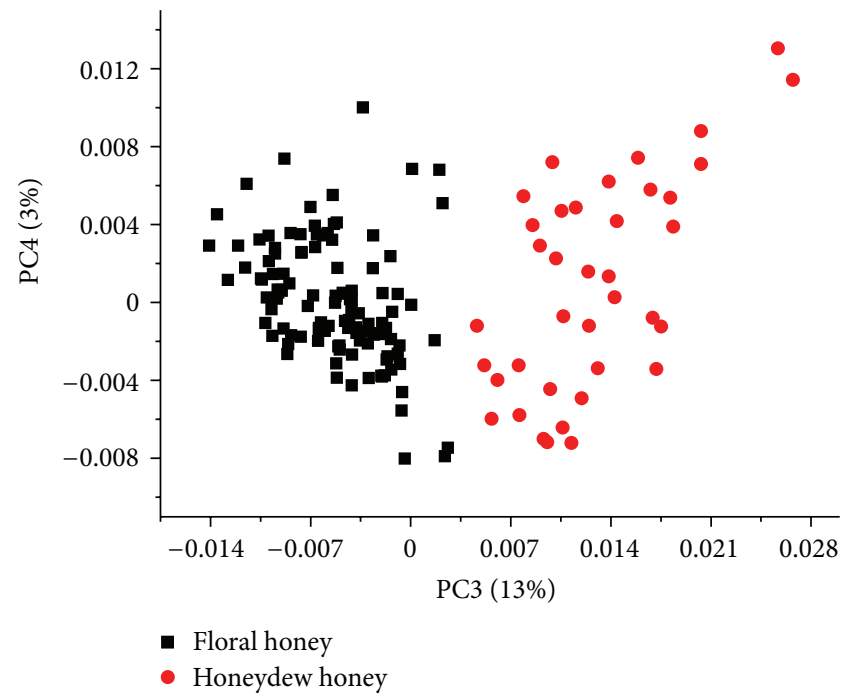

(a)

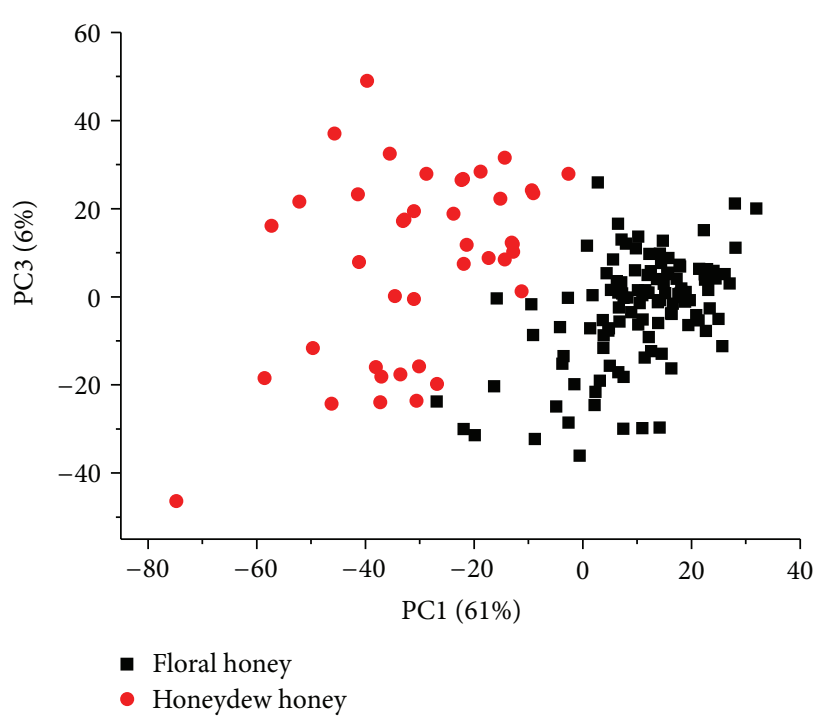

(b)

FIGURE 2: Scatter plot of the PCA scores of floral and honeydew honeys obtained from ${ }^{1} \mathrm{H}$ NMR (9-0.25 ppm; no scaling (a)) and ${ }^{13} \mathrm{C}$ NMR (200-0.25 ppm; scaling to unit variance (b)).

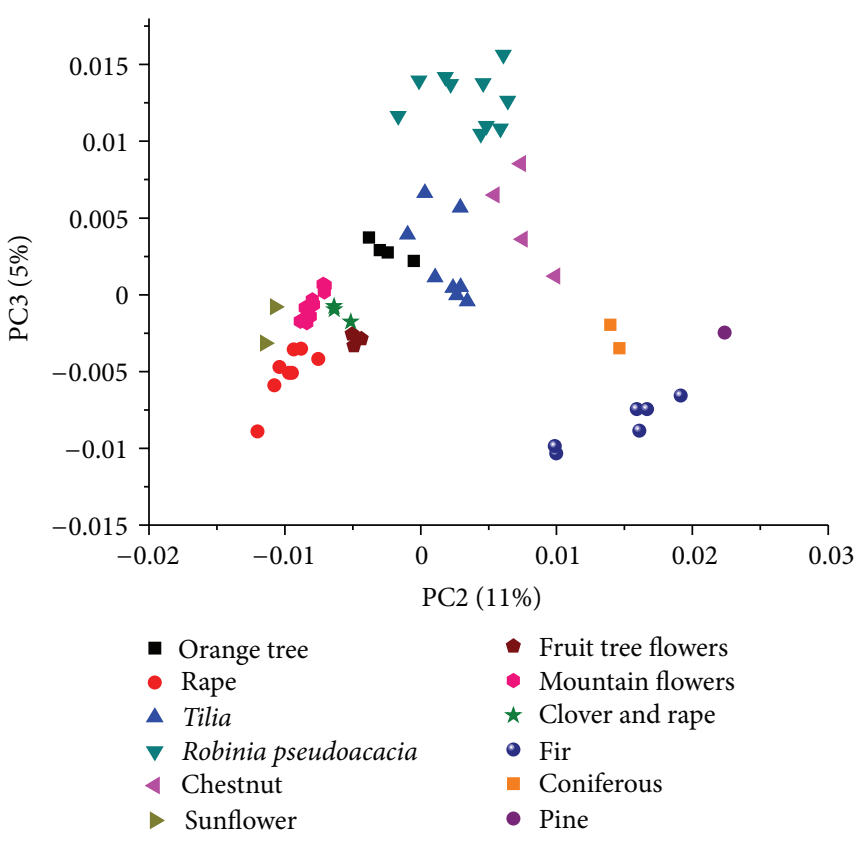

(a)

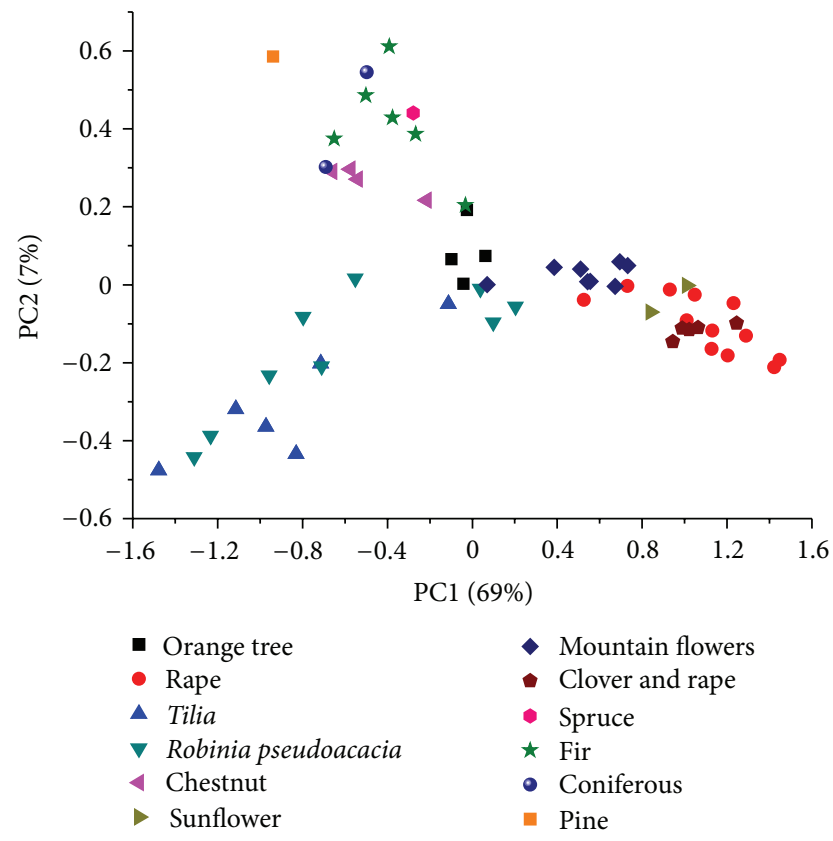

(b)

Figure 3: Scatter plot of the PCA scores of different types of unifloral honeys obtained from ${ }^{1} \mathrm{H}$ NMR (9-0.25 ppm; Pareto scaling (a)) and ${ }^{13}$ C NMR (200-0.25 ppm; no scaling (b)).

saccharose, barbituric acid (Merck, Darmstadt, Germany); $\mathrm{L}(+)$-rhamnose, arabinose, maltotriose, $\mathrm{D}(+)$-turanose, $\mathrm{D}(+)$-mannose, $\mathrm{D}(+)$-xylose, $\mathrm{D}(+)$-trehalosedihydrate, $\mathrm{D}(+)$-melezitose monohydrate, $\mathrm{D}(+)$-raffinosepentahydrate, malonic acid, pyruvic acid, and DL-proline (Fluka, Buchs, Switzerland); gluconic acid (calcium salt), and succinic acid (Carl Roth, Karlsruhe, Germany). The NMR buffer was prepared by dissolving $10.21 \mathrm{~g}$ of $\mathrm{KH}_{2} \mathrm{PO}_{4}$ and $9.75 \mathrm{mg}$ of sodium azide in $50 \mathrm{~mL}$ of pure water and then by adjusting the $\mathrm{pH}$ to 4.5 with $\mathrm{H}_{3} \mathrm{PO}_{4}$ or $\mathrm{KOH}$.

2.2. Sample Preparation and Calibration. The water content was obtained for each honey before NMR measurement using the German reference refractometric method [32]. The equivalent of $200 \mathrm{mg}$ water-free honey (about $240 \mathrm{mg}$ ) was weighted and combined with $300 \mu \mathrm{L}$ of NMR buffer 


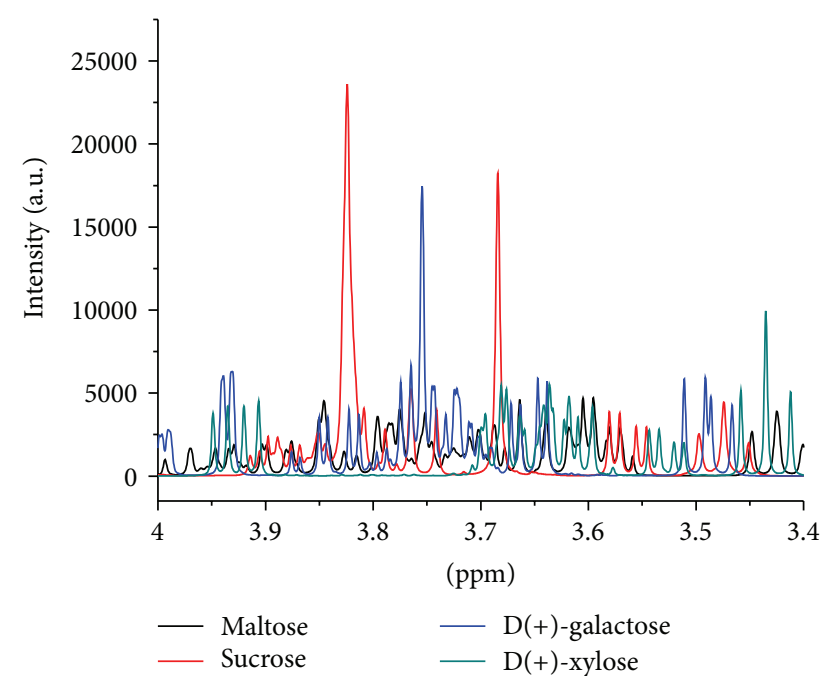

FIgURE 4: NMR spectra of maltose, sucrose, D(+)-galactose, and $\mathrm{D}(+)$-xylose standards in the mid-field region.

(see above), $700 \mu \mathrm{L}$ of distilled water and $100 \mu \mathrm{L}$ of an internal standard $\left(\mathrm{D}_{2} \mathrm{O}\right.$ containing $0.1 \%$ of TSP (sodium salt of 3(trimethylsilyl)-propionate acid-d4)). Stock solutions were prepared by mixing of about $20 \mathrm{mg}$ of a pure substance in $300 \mu \mathrm{L}$ of NMR buffer, $700 \mu \mathrm{L}$ of distilled water, and $100 \mu \mathrm{L}$ of an internal standard. For neutralization of organic acids, 1$2 \mu \mathrm{L}$ of $1 \mathrm{M} \mathrm{NaOH}$ were added to solutions because the buffer capacity of our NMR buffer was not otherwise sufficient to maintain a constant $\mathrm{pH}$ of 4.5 for these standard solutions. By diluting the stock solutions, several calibration standards were further prepared. $600 \mu \mathrm{L}$ of the final solution were poured into an NMR tube for direct measurement. For quantification, linear calibration curves were constructed from the standards by integrating the specific resonances for each compound against TSP as an intensity reference.

\section{3. ${ }^{1} \mathrm{H}$ and ${ }^{13} \mathrm{C}$ NMR Measurements at $400 \mathrm{MHz}$. All NMR} measurements were performed on a Bruker Avance 400 Ultrashield spectrometer (Bruker BioSpin, Rheinstetten, Germany) equipped with a $5 \mathrm{~mm}$ SEI probe with Z-gradient coils, using a Bruker Automatic Sample Changer (B-ACS 120). ${ }^{1} \mathrm{H}$ NMR spectra were acquired at $300.0 \mathrm{~K}$ without sample rotation. 64 scans and 4 prior dummy scans of $65 \mathrm{k}$ points were acquired with a spectral width of $19.9914 \mathrm{ppm}$, a receiver gain of 22.6, and an acquisition time of $4.096 \mathrm{~s}$. Water suppression was achieved using the NOESY-presaturation pulse sequence (Bruker $1 \mathrm{D}$ noesygpprld pulse sequence) with irradiation at the water frequency $(1890.60 \mathrm{~Hz})$ during the recycle and mixing time delays. ${ }^{13} \mathrm{C}$ NMR spectra were acquired using a Bruker zgpg30 pulse sequence with 1024 scans and 4 prior dummy scans. The sweep width was $238.9 \mathrm{ppm}$, the time domain of the FID was $66 \mathrm{k}$, receiver gain of 2050, and an acquisition time of $1.38 \mathrm{~s}$. The data were acquired automatically under the control of ICON-NMR (Bruker BioSpin, Rheinstetten, Germany), requiring about 91 min per sample (for both ${ }^{1} \mathrm{H}$ and ${ }^{13} \mathrm{C}$ NMR). All NMR spectra were phased, baseline-corrected, and calibrated by the TSP signal at $0.0 \mathrm{ppm}$.

2.4. NMR Spectra Preprocessing and Chemometrics. Multivariate data analysis was performed using Unscrambler $\mathrm{X}$ version 10.0.1 (CAMO Software AS, Oslo, Norway) and Amix version 3.9.4 (Bruker BioSpin, Rheinstetten, Germany). First, to cope with small variations in $\mathrm{pH}$ or other sample conditions such as ionic strength or temperature, simple rectangular bucket tables were obtained from the complete sets of ${ }^{1} \mathrm{H}$ and ${ }^{13} \mathrm{C}$ NMR spectra. In both cases, scaling to total intensity was used. Further details on the bucketing process of NMR spectra for multivariate data analysis were previously described [33]. Before multivariate analysis, all data were mean centered. In the context of this study, principal component analysis (PCA) was used for visualization and as a tool for a differentiation between different honey types. During PCA, several new axes instead of old variables (buckets) called principal components (PC) are calculated and each NMR spectrum is projected on the selected PCs resulting in the scatter plot. We tested several spectral regions for calculation: $\delta 0-3 \mathrm{ppm}, \delta 3-6 \mathrm{ppm}, \delta 6-10 \mathrm{ppm}$, and $\delta 0-10 \mathrm{ppm}$ for ${ }^{1} \mathrm{H}$ NMR and $\delta 0-45 \mathrm{ppm}, \delta 45-135 \mathrm{ppm}, \delta 135-200 \mathrm{ppm}$, and $\delta 0-200 \mathrm{ppm}$ for ${ }^{13} \mathrm{C}$ NMR. In cases when the whole spectral range was used, two preprocessing methods (scaling to unit variance and Pareto scaling) [34] as well as no scaling were tested for each data set in order to eliminate the magnitude effect of intensity variations in the $\delta 0-3 \mathrm{ppm}$ and $\delta 6-$ $10 \mathrm{ppm}$ regions. The bucket width was $0.01 \mathrm{ppm}$ in all cases. The technique of cross-validation was applied to determine the optimal number of principal components (PCs) required to obtain robust models. Kruskal-Wallis one-way analysis of variance, Shapiro-Wilk test, and Welch's $t$-test methods were used to analyze loadings plots in order to find out the most important buckets for differentiation. After the construction of the models to evaluate the classification performance, soft independent modeling of class analogy (SIMCA) and partial least squares-discriminant analysis (PLS-DA) classification methods were tested on randomly chosen test-set samples that were not included in the classification models.

\section{Results and Discussion}

3.1. Nontargeted Multivariate Analysis. Figure 1 shows the complete ${ }^{1} \mathrm{H}$ NMR spectra of tilia (or linden), Robinia pseudoacacia (or acacia), and fir honeys. It can be seen that the mid-low-frequency region between $\delta 4.2$ and $3.0 \mathrm{ppm}$ is dominated with very intensive signals of the major monosaccharides (glucose and fructose) and disaccharides (maltose and sucrose). Other less intensive resonances are also observed in the $\delta 9.0-6.0 \mathrm{ppm}$ and $\delta 2.5-1.0 \mathrm{ppm}$ regions in ${ }^{1} \mathrm{H}$ NMR spectra of honey. The ${ }^{13} \mathrm{C}$ NMR spectra of honey investigated in our study were similar to those obtained previously in $\mathrm{D}_{2} \mathrm{O}$ [35]. Most of the ${ }^{13} \mathrm{C}$ NMR signals were related to anomeric carbons of reducing and nonreducing sugars and were present in the $\delta 105-60 \mathrm{ppm}$ region in the majority of samples. Due to the high spectral complexity, differences between honey types cannot be obtained without 


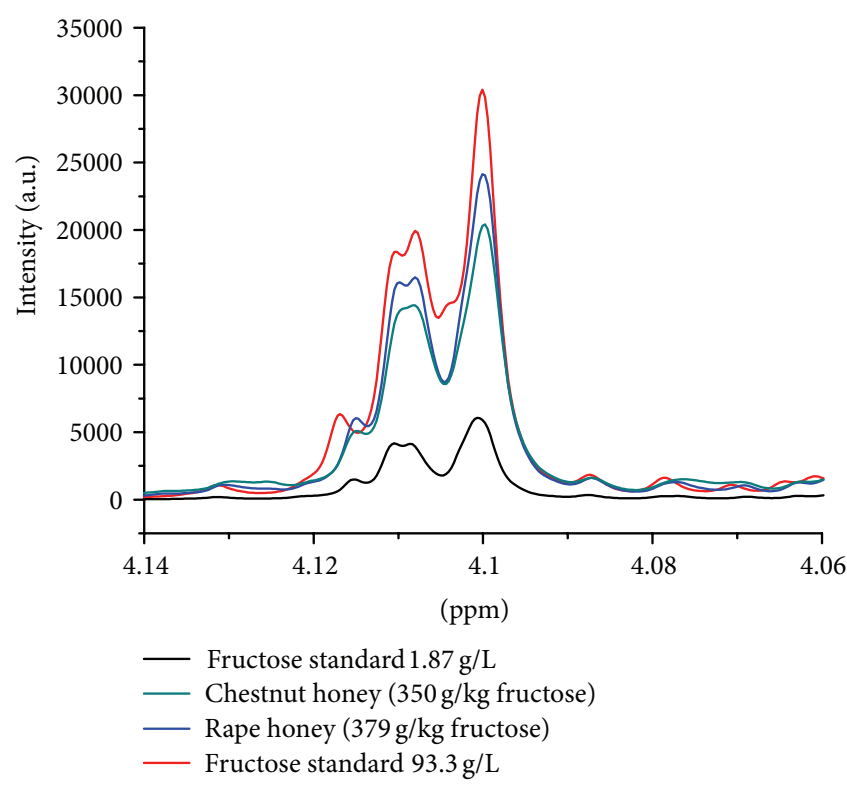

(a)

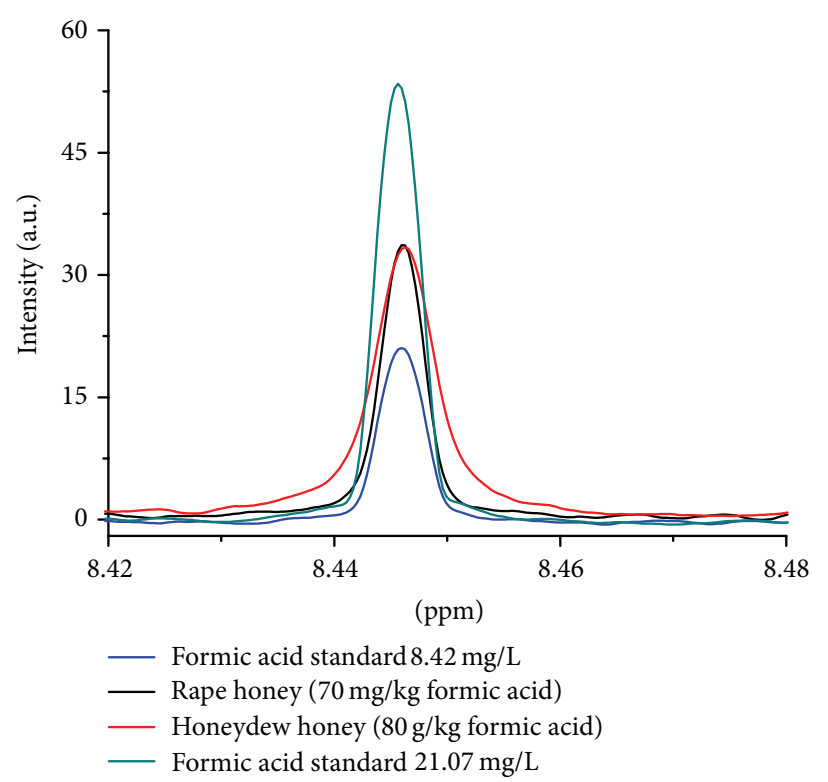

(b)

Figure 5: $400 \mathrm{MHz}{ }^{1} \mathrm{H}$ NMR spectra of fructose (a) and formic acid (b) in standard solutions and honey samples.

multivariate techniques. In general, the NMR spectra of our honey samples could be classified into two major groups: polyfloral samples (with floral and honeydew (forest flower honeys) as subgroups) and unifloral honeys (such as rape, tilia, chestnut, and others).

The PCA score plots generated using PC3-PC4 $\left({ }^{1} \mathrm{H}\right.$ NMR $)$ and PC1-PC3 $\left({ }^{13} \mathrm{C}\right.$ NMR) to visualize the separation of the polyfloral honeys are shown in Figure 2, which clearly suggests that the samples can be separated into two groups: honeydew honeys clusters are in the region of positive PC3 $\left({ }^{1} \mathrm{H}\right.$ NMR) and negative $\mathrm{PCl}\left({ }^{13} \mathrm{C}\right.$ NMR), respectively; floral honey samples are located in the negative values of $\mathrm{PC} 3\left({ }^{1} \mathrm{H}\right.$ $\mathrm{NMR})$ and positive PC1 ( ${ }^{13} \mathrm{C}$ NMR) values. Furthermore, Figure 3 suggests that we could not only differentiate the two main polyfloral classes of honey but clusters from several unifloral honeys were also clearly separated from each other. It should be noted that the ${ }^{13} \mathrm{CNMR}$ spectra provided inferior discrimination power as ${ }^{1} \mathrm{H}$ NMR spectra. For example, the PCA scores of rape and sunflower honeys or tilia, sunflower and Robinia pseudoacacia honeys were mixed in the same cluster (Figure 3(b)). With ${ }^{1} \mathrm{H}$ NMR spectra even minor differences in botanical composition can be traced (e.g., rape and rape/clover honeys are occurring in two separate clusters). On both scatter plots, honey samples from coniferous (spruce, fir, and pine trees) were clearly distinguished from the other honey types.

Loadings plots allow to specify the variables (chemical shifts), which are responsible for the observed clustering for both data sets $\left({ }^{1} \mathrm{H}\right.$ and ${ }^{13} \mathrm{C}$ NMR). Table 1 lists the most important buckets (signals) for different honey types obtained from the loadings plots. It was found that the signals of glucose and fructose play the key factor for differentiation, and this finding is in accordance with another NMR study of honeys [35]. However, resonances of minor compounds also play a certain role such as quinoline alkaloids and kynurenic acid for chestnut honey $[36,37]$ or unsaturated carboxylic acids for tilia honey [37]. Therefore, the ${ }^{1} \mathrm{H}$ NMR honey profile can be used for the identification of chemical markers of different botanical origin.

Next, it is interesting to show the predictive power of the chemometric methods by classifying new samples. To do this, two data analysis methods (SIMCA and PLS-DA) were evaluated for predicting class membership of honey samples from the ${ }^{1} \mathrm{H}$ NMR spectra. The independent test set for the flo$\mathrm{ral} /$ honeydew honey model (honeydew) consisted of 20 randomly selected objects (10 floral, 10 honeydew honeys). For the unifloral honey model, mountain $(n=2)$, rape $(n=3)$, coniferous $(n=2)$, Robinia pseudoacacia $(n=3)$, and chestnut $(n=1)$ honeys were selected for the test data set. The rest of the available ${ }^{1} \mathrm{H}$ NMR spectra were included in the calibration data set. All samples from both test sets were correctly recognized by SIMCA method at the $10 \%$ significance level. A prediction ability of $95 \%$ was obtained by PLS-DA for the honeydew/flower honey model. Thus, our results have shown that ${ }^{1} \mathrm{H}$ NMR coupled with multivariate statistics is an efficient tool for the classification of the different botanical origins of honey samples.

3.2. Quantification Studies. Besides the classification of botanical origin of honey samples, it would be advantageous to establish a NMR method for the quantification of main constituents in the honey matrix. As first evaluation, if a quantitative approach is at all possible from the NMR spectra, we measured 34 commercially available compounds that may be present in honey. Then, the spectra of standards were compared to the spectra of honey samples. For most of 
TABLE 1: The most important variables (buckets) for the differentiation of different botanical origins of honey (chemical shifts are given in $\mathrm{ppm}$ ).

\begin{tabular}{|c|c|c|}
\hline Botanical origin of honey & ${ }^{1} \mathrm{H}$ NMR & ${ }^{13} \mathrm{C}$ NMR \\
\hline Honeydew/floral & $\begin{array}{c}1.17-1.20 \\
3.26 \\
3.90-4.12 \\
3.43-3.50 \\
3.57-3.68\end{array}$ & $\begin{array}{c}101.49 \\
95.85 \\
69.19-76.11 \\
82.01\end{array}$ \\
\hline Coniferous & $\begin{array}{c}3.84-3.87 \\
3.61-3.67 \\
3.76-3.77 \\
4.05-4.07 \\
4.20-4.22 \\
5.24 \\
\end{array}$ & $\begin{array}{c}62.84 \\
69.44-69.53 \\
71.49-71.47\end{array}$ \\
\hline Rape & $\begin{array}{l}4.64-4.66 \\
3.40-3.46 \\
3.36-3.38 \\
4.05-4.07\end{array}$ & $\begin{array}{c}75.81-75.88 \\
74.22\end{array}$ \\
\hline Clover and rape & $\begin{array}{c}7.65-7.95 \\
5.89 \\
5.59\end{array}$ & $\begin{array}{c}69.64-69.74 \\
95.92\end{array}$ \\
\hline Sunflower & $3.25-3.27$ & \\
\hline Robinia pseudoacacia & $\begin{array}{c}3.69 \\
3.75 \\
3.43-3.44\end{array}$ & $69.24-69.75$ \\
\hline Tilia & $\begin{array}{c}1.38-1.41 \\
1.58-1.60 \\
2.34-2.35 \\
6.10-6.20 \\
7.65-7.66 \\
7.21-7.28 \\
\end{array}$ & $\begin{array}{c}63.96-63.97 \\
60.81 \\
67.64 \\
75.89\end{array}$ \\
\hline Chestnut & $\begin{array}{c}4.32-4.34 \\
5.09 \\
7.68-7.71 \\
7.45-7.49 \\
\end{array}$ & $\begin{array}{c}71.45-71.49 \\
60.58\end{array}$ \\
\hline Mountain honey & $3.88-3.91$ & $\begin{array}{c}95.90 \\
60.79-60.80 \\
69.68\end{array}$ \\
\hline Orange tree & $\begin{array}{c}8.13 \\
3.88-3.91\end{array}$ & $\begin{array}{l}62.75 \\
98.08 \\
75.49 \\
\end{array}$ \\
\hline Fruit tree flowers & $3.44-3.45$ & $-^{\mathrm{a}}$ \\
\hline
\end{tabular}

$\overline{{ }^{a} \text { No distinct cluster was obtained for fruit tree flowers with 13C NMR spectra. }}$

the substances studied, direct quantification with integration is not possible due to extensive spectra overlap. As an example, the spectra of four carbohydrates are shown in Figure 4. Clearly, a large number of overlapped signals for all isomeric forms of sugars exist. Thus, for such compounds more advanced techniques, such as multivariate regression or curve deconvolution, are required for quantification. Moreover, the two main carbohydrates-glucose and fructose-have much higher peak intensities than other compounds and, therefore, obscure the rest of the signals.

However, we were able to find 13 metabolites for which at least one resolved unambiguous resonance could be identified. Selected ${ }^{1}$ H NMR peaks (i.e., signals not overlapped
TABLE 2: NMR integration regions and investigated linear concentration ranges.

\begin{tabular}{lcc}
\hline Compound & NMR range & $\begin{array}{c}\text { Working range } \\
(\mathrm{mg} / \mathrm{kg})\end{array}$ \\
\hline HMF & $9.43-9.47 \mathrm{ppm}$ (singlet) & $20-600$ \\
Formic acid & $8.44-8.47 \mathrm{ppm}$ (singlet) & $40-1400$ \\
Phthalic acid & $7.53-7.48 \mathrm{ppm}$ (multiplet) & $30-900$ \\
Fumaric acid & $6.53-6.55 \mathrm{ppm}$ (singlet) & $20-670$ \\
Pyruvic acid & $6.42-6.45 \mathrm{ppm}$ (singlet) & $180-5000$ \\
L(+)-rhamnose & $5.13-5.09 \mathrm{ppm}$ (doublet) & $160-2500$ \\
Glucose & $4.63-4.65 \mathrm{ppm}$ (singlet) & $13-43000$ \\
Arabinose & $4.52-4.54 \mathrm{ppm}$ (singlet) & $40-1200$ \\
L(+)-tartaric acid & $4.32-4.35$ (singlet) & $90-2600$ \\
Fructose & $4.14-4.08$ (doublet) & $11-46000$ \\
Malic acid & $2.73-2.70$ (two singlets) & $30-1000$ \\
Citric acid & $2.69-2.68$ (singlet) & $40-1300$ \\
Succinic acid & $2.50-2.52$ (singlet) & $10-800$ \\
\hline
\end{tabular}

or interfered by matrix) corresponding to each substance are shown in Table 2 . The high correlation coefficients $(R>$ 0.99) obtained for each calibration graph indicate a good linear response within the concentration range studied for each compound. As an example, Figure 5 shows the NMR peaks of the main carbohydrate fructose and formic acid in authentic honey samples in comparison with two exemplary reference spectra. We applied the aforementioned procedure to the identification and direct quantification of the selected substances in authentic honeys of different floral types $(n=$ 20) (Table 3). Only in two cases direct quantification of malic acid was not possible due to spectral interferences.

\section{Conclusions}

NMR spectroscopy has already been used in honey analysis to determine its botanical and geographical origin. In the paper of Lolli et al., 71 Italian honey samples (Robinia, chestnut, citrus, eucalyptus, and polyfloral) were analyzed by ${ }^{1} \mathrm{H}$ NMR and heteronuclear multiple bond correlation (HMBC) spectroscopy [35]. PCA and general discriminant analysis (GDA) were not able to group samples according to their botanical origin by using ${ }^{1} \mathrm{H}$ NMR data. Only with the use of 2D 1H-13C HMBC acceptable clustering occurred [35]. In another article by this research group, HMBC spectroscopy in combination with GDA was used to detect $10 \%, 20 \%$, and $40 \%$ adulteration of authentic honey by commercial sugar syrups [38]. ${ }^{1} \mathrm{H}$ NMR spectroscopy and multivariate analysis techniques have also been used to classify honey into two geographical groups (non-Corsican and Corsican samples) [30]. 96.2\% correct classification obtained by cross-validation was obtained for partial least squares-genetic programming (PLS-GP) algorithm. It should be also noted that the sitespecific natural isotopic fraction NMR (SNIF-NMR) was not found to be successful for the characterization of geographical and botanical origins of honey [26]. However, to be used in practice, it would be necessary to extend the domain of 
TABLE 3: Results of the quantitative determination of substances by NMR (values are given in $\mathrm{g} / \mathrm{kg}$ honey).

\begin{tabular}{|c|c|c|c|c|c|c|c|c|c|c|c|c|c|}
\hline Sample & HMF & $\begin{array}{l}\text { Formic } \\
\text { acid }\end{array}$ & $\begin{array}{l}\text { Phthalic } \\
\text { acid }\end{array}$ & $\begin{array}{l}\text { Fumaric } \\
\text { acid }\end{array}$ & $\begin{array}{l}\text { Pyruvic } \\
\text { acid }\end{array}$ & $\begin{array}{c}\mathrm{L}(+)- \\
\text { rhamnose }\end{array}$ & Glucose & Arabinose & $\begin{array}{c}\mathrm{L}(+)- \\
\text { tartaric } \\
\text { acid }\end{array}$ & Fructose & $\begin{array}{l}\text { Malic } \\
\text { acid }\end{array}$ & $\begin{array}{l}\text { Citric } \\
\text { acid }\end{array}$ & $\begin{array}{l}\text { Succinic } \\
\text { acid }\end{array}$ \\
\hline Manuka honey & 0.03 & 0.15 & n.d. & n.d. & n.d. & n.d. & 218 & 0.41 & 0.31 & 284 & n.d. & 0.09 & 0.03 \\
\hline Flower honey & n.d. ${ }^{\mathrm{a}}$ & 0.05 & n.d. & n.d. & n.d. & n.d. & 350 & 0.18 & 0.31 & 357 & 0.2 & n.d. & 0.01 \\
\hline Sunflower honey & 0.05 & 0.06 & n.d. & 0.03 & n.d. & n.d. & 348 & 0.26 & 0.38 & 379 & 0.4 & 0.49 & 0.01 \\
\hline Honeydew honey & n.d. & 0.08 & n.d. & 0.02 & n.d. & n.d. & 219 & 0.41 & 0.58 & 314 & n.d. & 0.25 & 0.17 \\
\hline Chestnut honey & 0.06 & 0.71 & n.d. & 0.05 & n.d. & n.d. & 215 & 0.56 & 0.64 & 350 & n.d. & n.d. & 0.08 \\
\hline Flower honey & n.d. & 0.15 & n.d. & 0.04 & n.d. & n.d. & 271 & 0.49 & 0.59 & 312 & 0.9 & n.d. & 0.1 \\
\hline $\begin{array}{l}\text { Robinia pseudoacacia } \\
\text { honey }\end{array}$ & 0.06 & 0.04 & n.d. & n.d. & n.d. & 0.23 & 245 & 0.29 & 0.48 & 381 & n.d. & 0.17 & 0.01 \\
\hline Orange honey & 0.09 & 0.06 & n.d. & n.d. & n.d. & n.d. & 281 & 0.47 & 0.61 & 390 & 0.25 & 0.26 & 0.02 \\
\hline Flower honey & n.d. & 0.07 & n.d. & n.d. & n.d. & 2.6 & 337 & 0.26 & 0.35 & 358 & $-^{\mathrm{b}}$ & n.d. & 0.02 \\
\hline $\begin{array}{l}\text { Flower honey } \\
\text { (mountain) }\end{array}$ & 0.02 & 0.04 & n.d. & n.d. & n.d. & n.d. & 318 & 0.17 & 0.38 & 366 & n.d. & 0.1 & n.d. \\
\hline Rape honey & 0.01 & 0.07 & n.d. & n.d. & n.d. & n.d. & 349 & 0.27 & 0.39 & 379 & n.d. & n.d. & 0.03 \\
\hline $\begin{array}{l}\text { Honey from fruit } \\
\text { trees }\end{array}$ & n.d. & 0.12 & n.d. & 0.03 & n.d. & n.d. & 296 & 0.88 & 0.44 & 338 & n.d. & n.d. & 0.04 \\
\hline Flower honey & 0.06 & 0.08 & n.d. & 0.03 & n.d. & n.d. & 297 & 0.24 & 0.46 & 366 & n.d. & n.d. & 0.03 \\
\hline Flower honey & 0.06 & 0.09 & n.d. & 0.03 & n.d. & n.d. & 316 & 0.32 & 0.47 & 382 & n.d. & n.d. & 0.07 \\
\hline Chestnut honey & n.d. & 0.8 & n.d. & 0.04 & n.d. & n.d. & 241 & 0.65 & 0.74 & 395 & n.d. & 0.19 & 0.18 \\
\hline Honeydew honey & 0.03 & 0.11 & n.d. & 0.04 & n.d. & n.d. & 259 & 0.52 & 0.66 & 352 & n.d. & 0.28 & 0.28 \\
\hline Flower honey & 0.03 & 0.11 & n.d. & n.d. & n.d. & n.d. & 260 & 0.34 & 0.54 & 406 & n.d. & n.d. & 0.03 \\
\hline Eucalyptus honey & 0.06 & 0.1 & n.d. & n.d. & n.d. & n.d. & 302 & 1.72 & 0.45 & 346 & 0.28 & n.d. & 0.06 \\
\hline Flower honey & n.d. & 0.63 & n.d. & n.d. & 1.45 & n.d. & 215 & 0.65 & 0.59 & 380 & n.d. & n.d. & 0.05 \\
\hline $\begin{array}{l}\text { Flower honey with } \\
\text { jelly Royal }\end{array}$ & 0.03 & 0.05 & n.d. & n.d. & n.d. & n.d. & 315 & 0.4 & 0.46 & 368 & $-{ }^{\mathrm{b}}$ & 0.17 & 0.02 \\
\hline
\end{tabular}

${ }^{a}$ Not detectable $(0.03 \mathrm{~g} / \mathrm{kg}$ (phthalic acid and malic acid), $0.02 \mathrm{~g} / \mathrm{kg}$ (HMF and fumaric acid), $0.18 \mathrm{~g} / \mathrm{kg}$ (pyruvic acid), $0.16 \mathrm{~g} / \mathrm{kg}$ (L(+)-rhamnose), 0.04 (citric acid), and $0.01 \mathrm{~g} / \mathrm{kg}$ (succinic acid)).

${ }^{\mathrm{b}}$ Overlapped signal, direct quantification is not possible.

application of the method for other unifloral honeys and to expand the database. Our study, which is the largest evaluation of honey samples by NMR so far, provides such an opportunity. We can conclude that our models can be used as a method to determine and monitor the botanical origin of honey samples.

With regard to quantification, NMR was only used for determining several saccharides with ${ }^{13} \mathrm{C}$ NMR [27] or methylglyoxal and amino acids with ${ }^{1} \mathrm{H}$ NMR [39] in honey matrices. Clearly, we expanded the range of substances that can be analyzed with NMR spectroscopy without preceding separation; ${ }^{1} \mathrm{H}$ NMR is also suitable for quantification of several aliphatic and aromatic acids as well as aldehydes.

In conclusion, it should be noted that honey is a very complex matrix endowed with very specific physicochemical properties. This complexity makes the analysis of honey difficult in terms of its different properties. Often the determination of botanical origin is complicated because of the incomplete correlation between analytical parameters: sensory properties and botanical identity.

Our investigation has shown that ${ }^{1} \mathrm{H}$ NMR spectra of honeys in combination with appropriate multivariate statistics can provide qualitative information about the botanical origin and represent a good basis for the identification of marker compounds for the specific honey types. Quantitative information about a number of major components is also available from the same spectra without need for chromatographic separation. In combination with multivariate data analysis, NMR spectroscopy possesses the speed, simplicity, and low cost per analysis required for a screening technique.

\section{Conflict of Interests}

The authors declare that there is no conflict of interests.

\section{Acknowledgments}

The authors are grateful to Margit Böhm, Bernd Siebler, Jürgen Geisser, Antje Theiner, Beate Wagner, Karin Wolff, and Klaus Klusch for their excellent technical assistance. The views expressed in this paper do not necessarily reflect those of the Ministry of Rural Affairs and Consumer Protection. 


\section{References}

[1] A. R. Aparna and D. Rajalakshmi, "Honey—its characteristics, sensory aspects, and applications," Food Reviews International, vol. 15, no. 4, pp. 455-471, 1999.

[2] J. Louveaux, A. Maurizio, and G. Vorwohl, "Methods of Melissopalynology," Bee World, vol. 59, no. 4, pp. 139-157, 1978.

[3] A. Zakaria, A. Y. Shakaff, M. J. Masnan et al., "A biomimetic sensor for the classification of honeys of different floral origin and the detection of adulteration," Sensors, vol. 11, no. 8, pp. 7799-7822, 2011

[4] P. Arquillue and A. H. Marteache, "Analysis of protein amino acids in some honeys from Los Monegros Spain," Alimentaria, vol. 24, no. 183, pp. 67-71, 1987.

[5] J. Prodolliet and C. Hischenhuber, "Food authentication by carbohydrate chromatography," Zeitschrift fur Lebensmittel Untersuchung und -Forschung, vol. 207, no. 1, pp. 1-12, 1998.

[6] L. A. Marghitas, D. S. Dezmirean, C. B. Pocol, M. Ilea, O. Bobis, and I. Gergen, "The development of a biochemical profile of acacia honey by identifying biochemical determinants of its quality," Notulae Botanicae Horti Agrobotanici Cluj-Napoca, vol. 38, no. 2, pp. 84-90, 2010.

[7] G. Beretta, R. Artali, E. Caneva, S. Orlandini, M. Centini, and R. M. Facino, "Quinoline alkaloids in honey: further analytical (HPLC-DAD-ESI-MS, multidimensional diffusionordered NMR spectroscopy), theoretical and chemometric studies," Journal of Pharmaceutical and Biomedical Analysis, vol. 50, no. 3, pp. 432-439, 2009.

[8] J. Gilbert, M. J. Shepherd, M. A. Wallwork, and R. G. Harris, "Determination of the geographical origin of honeys by multivariate-analysis of gas-chromatographic data on their free amino-acid content," Journal of Apicultural Research, vol. 20, no. 2, pp. 125-135, 1981.

[9] A. Terrab, B. V. Castrillón, and M. J. D. Dapena, "Pollen analysis of honeys from the Gharb region (NW Morocco)," Grana, vol. 40, no. 4-5, pp. 210-216, 2001.

[10] A. I. Ruiz-Matute, M. Brokl, A. C. Soria, M. L. Sanz, and I. Martínez-Castro, "Gas chromatographic-mass spectrometric characterisation of tri- and tetrasaccharides in honey," Food Chemistry, vol. 120, no. 2, pp. 637-642, 2010.

[11] L. Nagy, R. Bátai, G. Nagy, and G. Nagy, "Application of copper electrode based amperometric detector cell for LC analysis of main sugar component of honey and nectar," Analytical Letters, vol. 43, no. 7, pp. 1411-1426, 2010.

[12] S. R. Won, D. C. Lee, S. H. Ko, J. W. Kim, and H. I. Rhee, "Honey major protein characterization and its application to adulteration detection," Food Research International, vol. 41, no. 10, pp. 952-956, 2008.

[13] J. Wang, M. M. Kliks, W. Qu, S. Jun, G. Shi, and Q. X. Li, "Rapid determination of the geographical origin of honey based on protein fingerprinting and barcoding using MALDI TOF MS," Journal of Agricultural and Food Chemistry, vol. 57, no. 21, pp. 10081-10088, 2009.

[14] J. A. F. Pierna, O. Abbas, P. Dardenne, and V. Baeten, "Discrimination of Corsican honey by FT-Raman spectroscopy and chemometrics," Biotechnology, Agronomy and Society and Environment, vol. 15, no. 1, pp. 75-84, 2011.

[15] A. N. Batsoulis, N. G. Siatis, A. C. Kimbaris et al., "FT-Raman spectroscopic simultaneous determination of fructose and glucose in honey," Journal of Agricultural and Food Chemistry, vol. 53, no. 2, pp. 207-210, 2005.
[16] M. García-Alvarez, J. F. Huidobro, M. Hermida, and J. L. Rodríguez-Otero, "Major components of honey analysis by near-infrared transflectance spectroscopy," Journal of Agricultural and Food Chemistry, vol. 48, no. 11, pp. 5154-5158, 2000.

[17] L. Dvash, O. Afik, S. Shafir et al., "Determination by nearinfrared spectroscopy of perseitol used as a marker for the botanical origin of avocado (Persea americana Mill.) honey," Journal of Agricultural and Food Chemistry, vol. 50, no. 19, pp. 5283-5287, 2002.

[18] X. Zhu, S. Li, Y. Shan et al., "Detection of adulterants such as sweeteners materials in honey using near-infrared spectroscopy and chemometrics," Journal of Food Engineering, vol. 101, no. 1, pp. 92-97, 2010.

[19] D. Cozzolino, E. Corbella, and H. Smyth, "Quality control of honey using infrared spectroscopy: a review," Applied Spectroscopy Reviews, vol. 46, no. 7, pp. 523-538, 2011.

[20] L. Svecnjak, N. Biliskov, D. Bubalo, and D. Barisic, "Application of infrared spectroscopy in honey analysis," Agriculturae Conspectus Scientificus, vol. 76, no. 3, pp. 191-195, 2011.

[21] S. Hennessy, G. Downey, and C. P. O’Donnell, “Attempted confirmation of the provenance of corsican PDO honey using FT-IR spectroscopy and multivariate data analysis," Journal of Agricultural and Food Chemistry, vol. 58, no. 17, pp. 9401-9406, 2010.

[22] S. Sivakesava and J. Irudayaraj, "Classification of simple and complex sugar adulterants in honey by mid-infrared spectroscopy," International Journal of Food Science and Technology, vol. 37, no. 4, pp. 351-360, 2002.

[23] M. M. Paradkar, J. Irudayaraj, and S. Sakhamuri, "Discrimination and classification of beet and cane sugars and their inverts in maple syrup by FT-Raman," Applied Engineering in Agriculture, vol. 18, no. 3, pp. 379-383, 2002.

[24] H. Wang, Y. Q. Liu, H. M. Yang, Q. L. Guo, H. L. Shi, and L. B. Yan, "Determination of glucose, fructose, sucrose, maltose and lactose in sugar-free products by liquid chromatographytandem mass spectrometry," Chinese Journal of Analytical Chemistry, vol. 38, no. 6, pp. 873-876, 2010.

[25] T. Gallardo-Velázquez, G. Osorio-Revilla, M. Z. D. Loa, and Y. Rivera-Espinoza, "Application of FTIR-HATR spectroscopy and multivariate analysis to the quantification of adulterants in Mexican honeys," Food Research International, vol. 42, no. 3, pp. 313-318, 2009.

[26] J. F. Cotte, H. Casabianca, J. Lhéritier et al., "Study and validity of 13C stable carbon isotopic ratio analysis by mass spectrometry and $2 \mathrm{H}$ site-specific natural isotopic fractionation by nuclear magnetic resonance isotopic measurements to characterize and control the authenticity of honey," Analytica Chimica Acta, vol. 582, no. 1, pp. 125-136, 2007.

[27] V. Mazzoni, P. Bradesi, F. Tomi, and J. Casanova, "Direct qualitative and quantitative analysis of carbohydrate mixtures using C-13 NMR spectroscopy: application to honey," Magnetic Resonance in Chemistry, vol. 35, pp. S81-S90, 1997.

[28] R. Consonni and L. R. Cagliani, "Geographical characterization of polyfloral and acacia honeys by nuclear magnetic resonance and chemometrics," Journal of Agricultural and Food Chemistry, vol. 56, no. 16, pp. 6873-6880, 2008.

[29] E. Schievano, E. Peggion, and S. Mammi, "H-1 nuclear magnetic resonance spectra of chloroform extracts of honey for chemometric determination of its botanical origin," Journal of Agricultural and Food Chemistry, vol. 58, no. 1, pp. 57-65, 2010.

[30] J. A. Donarski, S. A. Jones, and A. J. Charlton, "Application of cryoprobe $\mathrm{H}-1$ nuclear magnetic resonance spectroscopy and 
multivariate analysis for the verification of corsican honey," Journal of Agricultural and Food Chemistry, vol. 56, no. 14, pp. 5451-5456, 2008.

[31] P. Sandusky and D. Raftery, "Use of selective TOCSY NMR experiments for quantifying minor components in complex mixtures: application to the metabonomics of amino acids in honey," Analytical Chemistry, vol. 77, no. 8, pp. 2455-2463, 2005.

[32] DIN 10752, Untersuchung von Honig; Bestimmung des Wassergehaltes, Refraktometrisches Verfahren, Berlin, Germany, 2012.

[33] D. W. Lachenmeier, W. Frank, E. Humpfer et al., "Quality control of beer using high-resolution nuclear magnetic resonance spectroscopy and multivariate analysis," European Food Research and Technology, vol. 220, no. 2, pp. 215-221, 2005.

[34] R. A. van den Berg, H. C. J. Hoefsloot, J. A. Westerhuis, A. K. Smilde, and M. J. van der Werf, "Centering, scaling, and transformations: improving the biological information content of metabolomics data," BMC Genomics, vol. 7, article 142, 2006.

[35] M. Lolli, D. Bertelli, M. Plessi, A. G. Sabatini, and C. Restani, "Classification of Italian honeys by 2D HR-NMR," Journal of Agricultural and Food Chemistry, vol. 56, no. 4, pp. 1298-1304, 2008.

[36] P. Truchado, I. Martos, L. Bortolotti, A. G. Sabatini, F. Ferreres, and F. A. Tomas-Barberan, "Use of quinoline alkaloids as markers of the floral origin of chestnut honey," Journal of Agricultural and Food Chemistry, vol. 57, no. 13, pp. 5680-5686, 2009.

[37] G. Beretta, E. Caneva, L. Regazzoni, N. G. Bakhtyari, and R. Maffei Facino, "A solid-phase extraction procedure coupled to H-1 NMR, with chemometric analysis, to seek reliable markers of the botanical origin of honey," Analytica Chimica Acta, vol. 620, no. 1-2, pp. 176-182, 2008.

[38] D. Bertelli, M. Lolli, G. Papotti, L. Bortolotti, G. Serra, and M. Plessi, "Detection of honey adulteration by sugar syrups using one-dimensional and two-dimensional high-resolution nuclear magnetic resonance," Journal of Agricultural and Food Chemistry, vol. 58, no. 15, pp. 8495-8501, 2010.

[39] J. A. Donarski, D. P. T. Roberts, and A. J. Charlton, “Quantitative NMR spectroscopy for the rapid measurement of methylglyoxal in manuka honey," Analytical Methods, vol. 2, no. 10, pp. 14791483, 2010. 

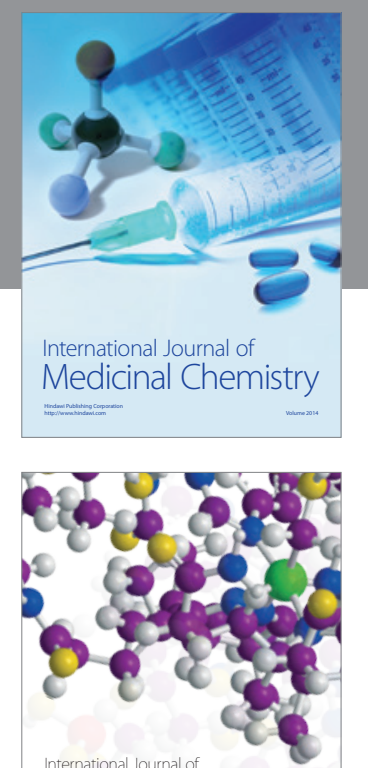

\section{Carbohydrate} Chemistry

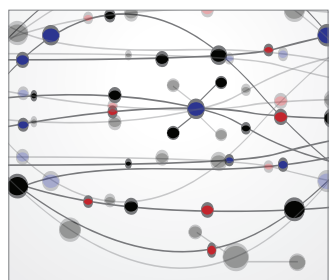

The Scientific World Journal
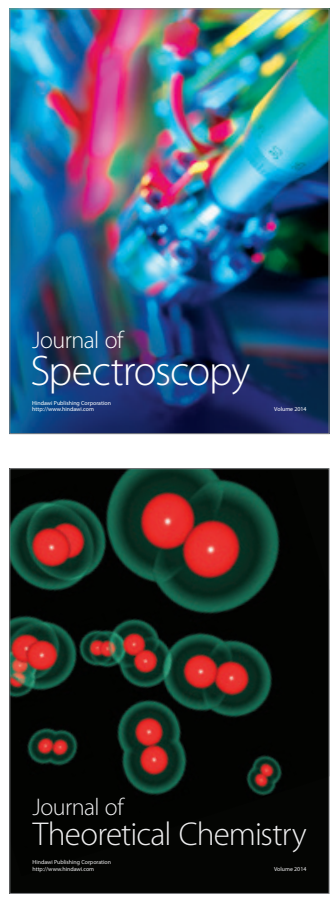
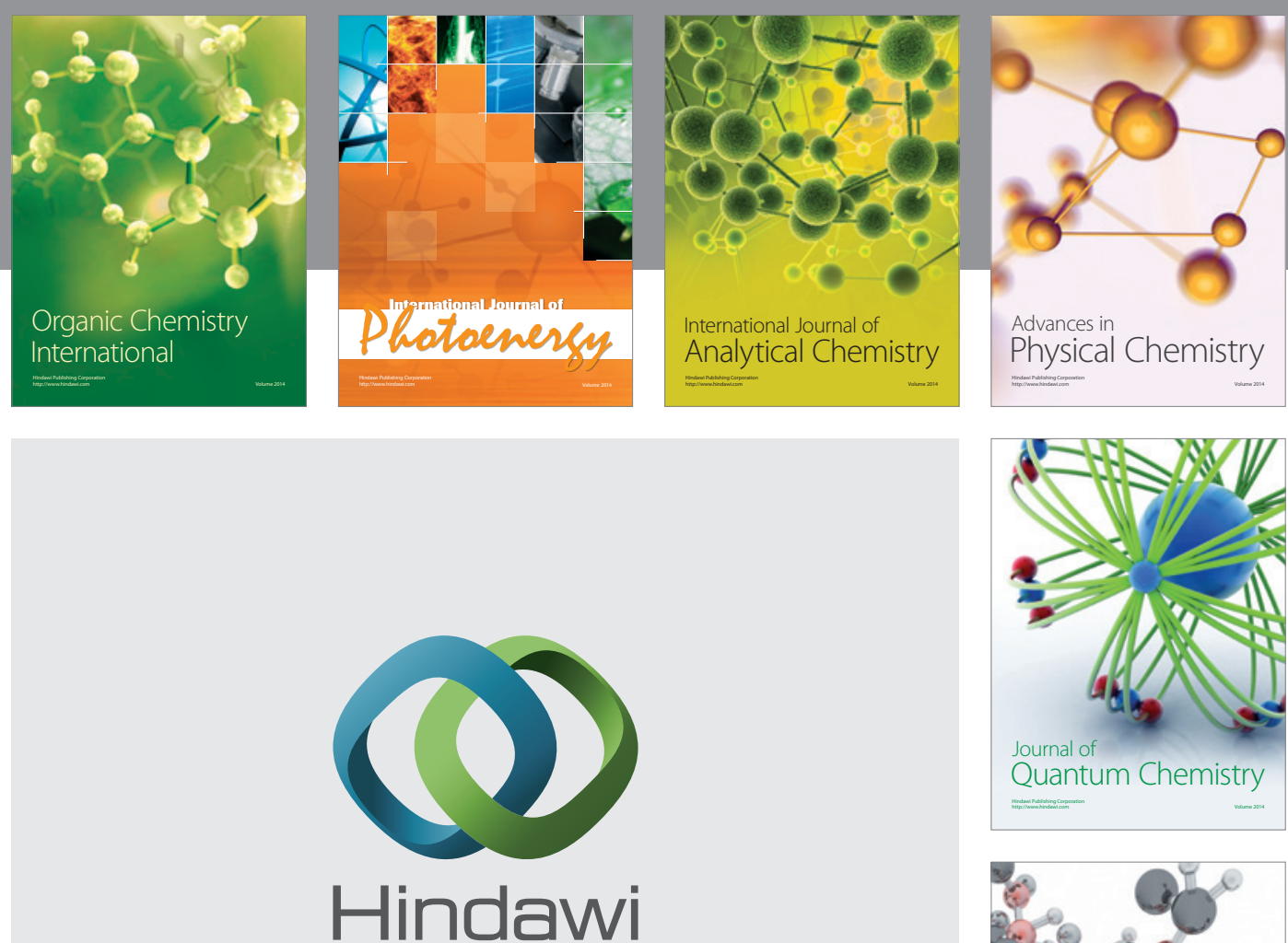

Submit your manuscripts at

http://www.hindawi.com

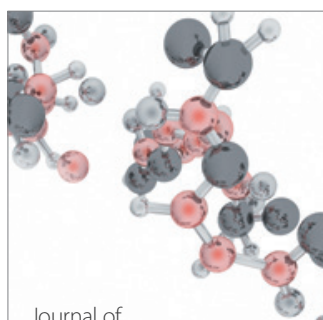

Analytical Methods

in Chemistry

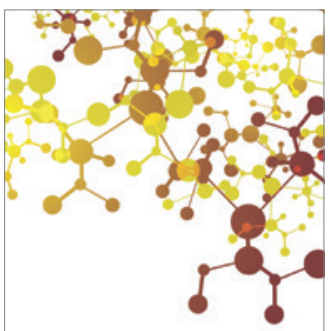

Journal of

Applied Chemistry

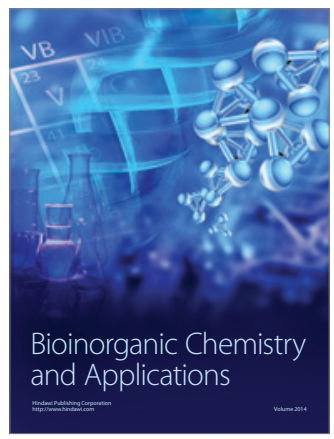

Inorganic Chemistry
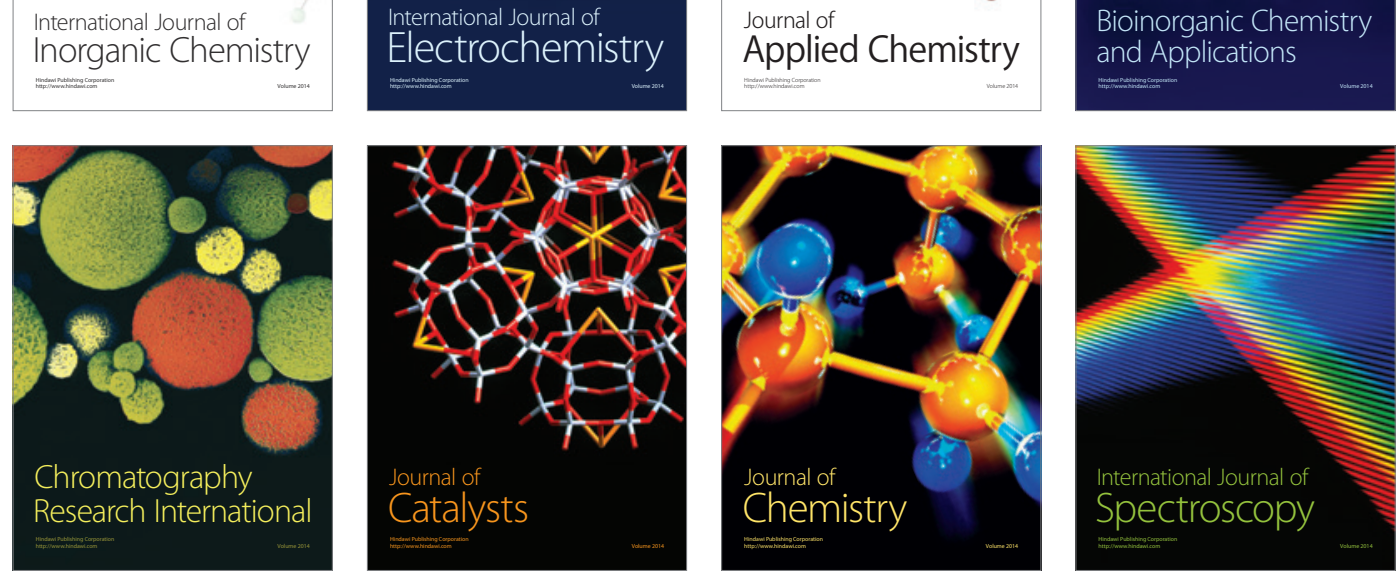